\title{
Relief formation of the Selenga River delta in different periods of water content during the technogenic stage of development
}

\author{
Elena Ilicheva ${ }^{1 *}$, Maksim Pavlov $^{1}$, Eseniya Shchipanova ${ }^{2}$, and Anastasia Gavrilova ${ }^{2}$ \\ ${ }^{1}$ V. B. Sochava Institute of Georaphy SB RAS, Ulan-Batorskaya 1, 664033, Irkutsk, Russia \\ ${ }^{2}$ Saint Petersburg State University, 7/9 Universitetskaya nab, 199034, St. Petersburg, Russia
}

\begin{abstract}
The technogenic stage of relief formation of the river mouth systems of the Lake Baikal coast occurred during the rise of the basic level in the 50-70 years of the last century and continues to the present time. In the considered stage, there were at least 6 anomalies of river flow, which caused the onset of low-water and high-water periods in the Baikal basin. Changes in the basic conditions of formation of the Baikal coast were significantly reflected in the morphology of the largest river mouth system of the Selenga River, representing the protruding delta. The fluvial process is leading in delta-forming and is controlled by the level of the receiving reservoir, hydro-climatic events in the basin and seismotectonic manifestations in the coastal zone. During the mentioned period at the top of the Delta, there was a change of the type of channel process, the restructuring of the channel network, the formation of flood-plain terrace, channel meso - and microforms was noted. Morphometric analysis of cartographic data allowed building a hydrological and geomorphological model development of the relief of the Delta, as well as for the time sections corresponding to the periods of low water and high water.
\end{abstract}

\section{Introduction}

Issues of relief formation and geomorphological mapping of the river mouth systems are widely reported in the Russian literature for the coasts of the Russian inland and marginal

\footnotetext{
*Corresponding author: lenail3663@mail.ru
} 
seas. A fundamental factor in the development of the river mouth areas is the geological and tectonic structure of the coastal zone, expressed by various degrees of indentation of the coastline and the presence of morphostructures that form a shallow or steep seaside. At the present stage, the fluvial process is the leading one for the relief formation of the river mouth systems in conjunction with regional geographical conditions; it forms certain channel and river mouth landforms that correspond to different morphogenetic types. Runoff of water and sediment, hydro-climatic conditions in the river basin, tectonic manifestations and technogenic intervention in the interaction of the river flow and the receiving reservoir create a modern appearance of the river mouth system. For the river mouth of the Selenga River, the formation of the Ust-Selenga depression in the Miocene [4, $6,8]$ and its subsequent filling with Neogene, Pleistocene and Holocene sediments created a shallow seaside on which the modern protruding delta is formed.

\section{Methods and object of research}

This study uses a cartographic method with a comparative analysis of the planned positions of the delta branches and morphometric characteristics of channel landforms formed in the runoff channels of the Selenga Delta during the technogenic stage of development, the beginning of which should be attributed to the time of the level rise and its regulation to the present time. The object of research is the channel network of the Selenga River Delta, consisting of seven main branches (Fig.1). The top of the modern Delta is located near the Maloe Kolesovo village. Downstream, the main river flow is divided into two main stream directions: Tvorogovo (left) and Krasnoyarovsko (right) [1, 3, 8]. The Islands that divide the main runoff are cut through by narrow (up to 3-5 m) delta channels, the runoff direction of which varies depending on the water content. Downstream from the main branching node $(14-16 \mathrm{~km})$, the runoff of the Tvorogovo direction is divided into two branches: the Kharauz (Main channel or Selenga) and the Levoberezhnaya. The runoff in the Krasnoyarovo direction also divides into the branches at the bifurcation node of the Manzar, Dologan, and Lobanovskaya channels $(11 \mathrm{~km})$. Sredneustye (central) runoff direction begins at bifurcation node at $9 \mathrm{~km}$ and is represented by three branches: Galutay, Sredneustye and Kolpinnaya. Channel network of central direction is provided by a runoff branch associated with Tvorogovo and Krasnoyarovo streams.

Topographical maps and satellite images corresponding to different periods of water content before the technogenic rise of the Baikal level and to subsequent hydro-climatic conditions in the Selenga river basin were selected as cartographic material for the object of study. The planned positions of the Delta branches were digitized for different time sections of the survey in the mid-range: 1952, 1980, 1993, and 2011 years. Maps and satellite image are shown in a single projection and scale, the hydro grid was digitized in $15 \mathrm{~m}$ increments, for each time section for correct calculation of morphometric parameters and comparison of planned positions. 


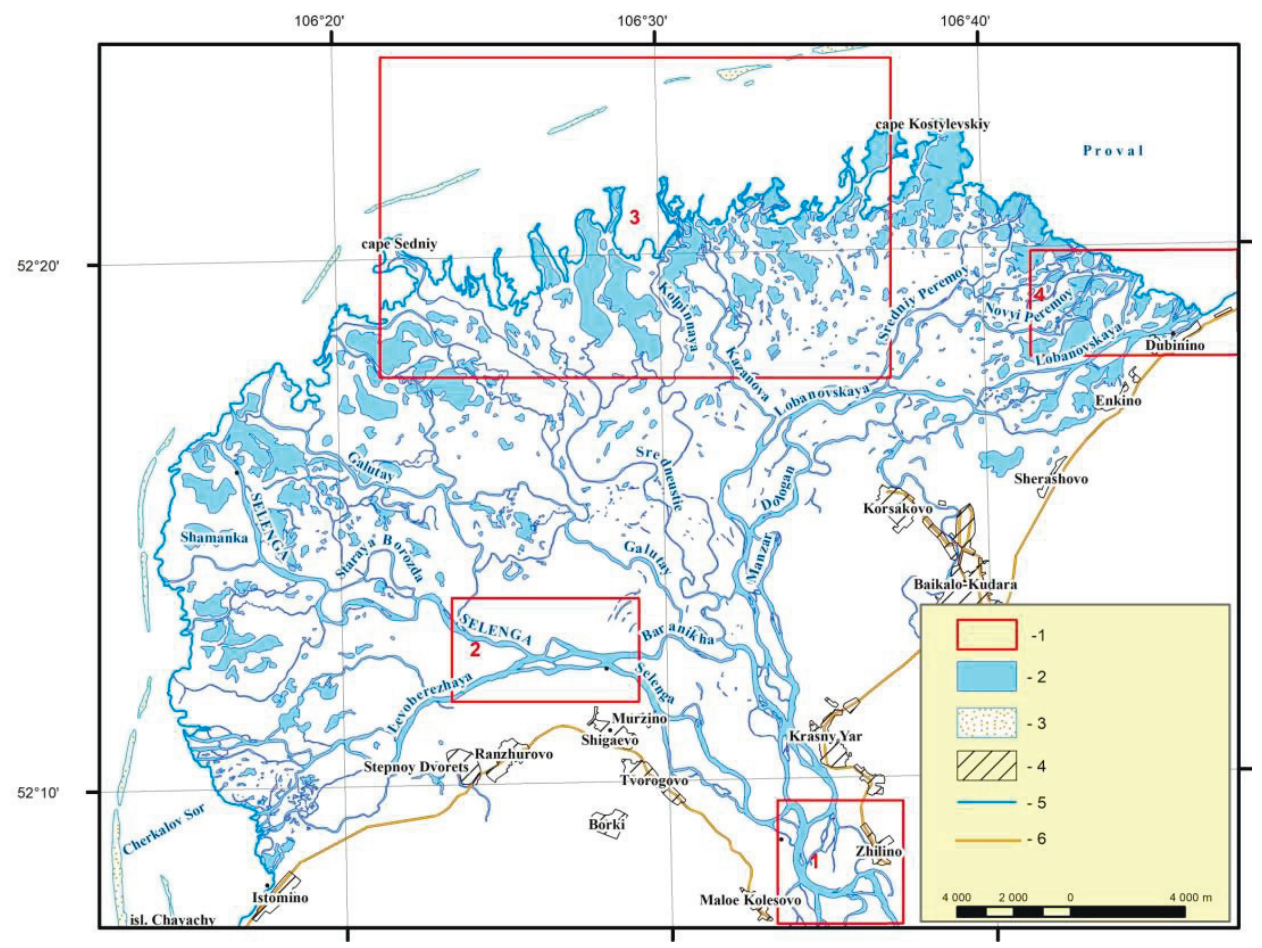

Fig. 1. The map of the Selenga River Delta and areas of maximum channel deformations: 1 - кеy areas; 2 - hydrographic network; 3 - subaquatic landforms (blocking sand bars); 4 - settlements; 5 coastline; 6 - highways.

\section{Results}

The water level in Lake Baikal is formed by inflow and drain through the Angara River. The largest stream tributary of Lake Baikal - the Selenga River brings more than half of the flow of all stream tributaries, 230 of which have a constant flow. Thus, long-term fluctuations in the flow of the Selenga river should be reflected in the long-term course of the Baikal levels. The longest course of the Baikal levels was reconstructed by A. N. Afanasyev from 1747, in which century-old cycles and intra-century rhythms were determined [2]. A number of data on Baikal amplitudes has been extended until 2015 with the specification of the boundaries of "high-water and low-water years" for the historical and modern periods [7]. In this study, the boundaries of periods of high and low water content in the Selenga River basin are determined by the deviation of the average annual flow from the average long-term water flow (Fig.2). 


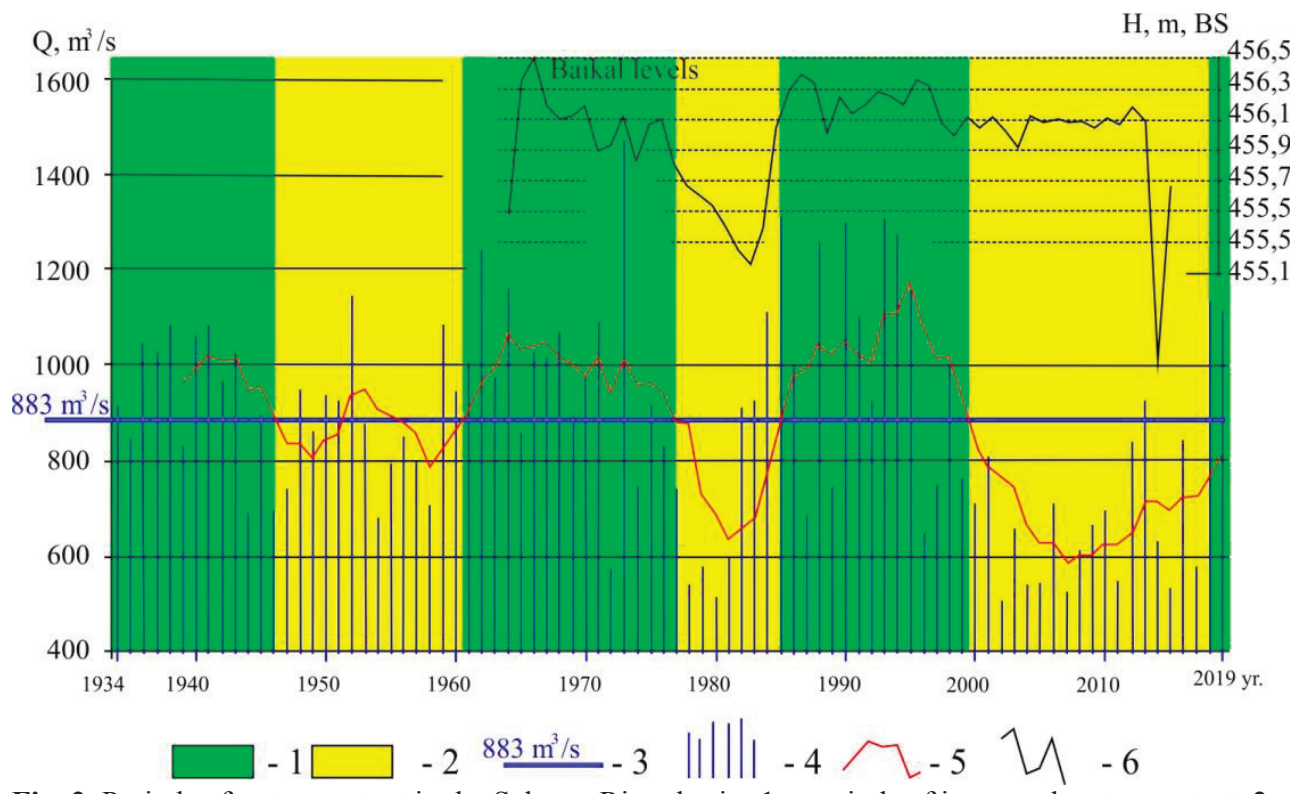

Fig. 2. Periods of water content in the Selenga River basin: 1 - periods of increased water content; 2 periods of reduced water content; 3 - the average long-term water flow in the Selenga River for the period from 1934 - 2019; 4 - average annual water discharge in the Selenga River; 5 - averaging curve of average annual water discharge in the Selenga River; 6 - average annual Baikal level.

There are at least three high-water anomalies (for 1946; 1961 - 1977; 1985 - 1999) and three low-water flow anomalies (from 1947 to 1960,1978 - 1984, 2000 - 2017), the last of which was the longest. The last 2018 - 2019 years should also be attributed to the beginning of a new stage of increased water content. Each of these periods is characterized by special parameters: duration, average, maximum and minimum values of flow. The graphic of the Selenga river water content curves and the Baikal level are mostly synchronous before the beginning of artificial regulation of the Lake, which indicates a significant impact of the flow of the largest tributary on the level. Regulation caused a change in the natural stage of development of the Baikal the river mouth systems and the Selenga River Delta in particular.

The influence of periods of high and low water content is reflected in the topography of the Delta, due to channel deformations, flooding of the Delta periphery and the extension of the river mouths (Fig. 3).

In the $1950 \mathrm{~s}$, the top of the Delta was a wide (up to $1.5 \mathrm{~km}$ ) straight channel with island and floodplain multi-branches. Downstream was bifurcated to Tvorogovo and Krasnoyarovo the direction of flow. The rise of the Baikal level of the Irkutsk reservoir caused flooding of the periphery of the Delta, reducing the slopes of the Delta branches, 
which led to the exit of river waters to the floodplains. During this period, there was a change of water content in the Selenga River basin. At the top of the Delta, a segmental river bend is formed by cutting into the right bank near the Zhilino village. The bifurcation node shifts downstream, eroding large high islands and creating floodplain terrace sand ridges relief. The left bank is eroded at 170-200 m.

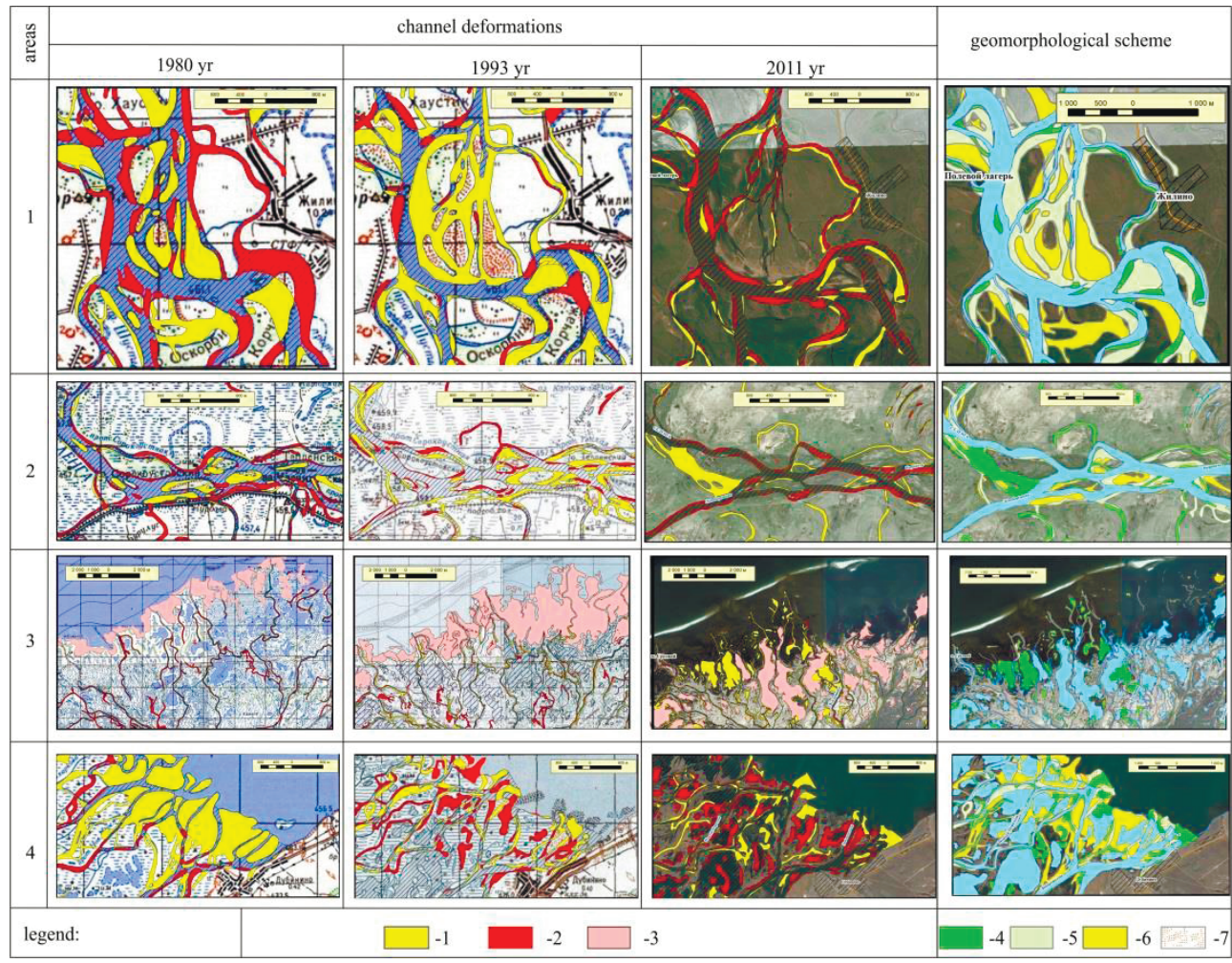

Fig. 3. Stages of the formation of fluvial relief in the Selenga River Delta: 1 - erosion; 2 accumulation; 3 - flooding and abrasion; 4 - floodplains formed in 1993-2011; 5 - floodplains formed in 1980-1993; 6 - floodplains formed in 1950-1980; 7 - subaquatic landforms.

During the period of low water content (by 1980), a new branch appeared - the Levoberezhnaya, which separates from the main channel (area 3) is characterized by flooding and erosion of the Delta periphery. The length of the river network was reduced and significant wetlands and limans were formed. The Delta is extended up to $2 \mathrm{~km}$, accumulative levees and bars and subdeltas are formed at the river mouths of the Selenga, Galutai and Lobanovskaya branches (area 4). 
The next stage is characterized by increased of water content, high levels of Lake Baikal and multidirectional manifestations of erosion and accumulative activity. At the top of the Delta, a segmental embedded river meander was formed with localized flow in a single channel $0.3 \mathrm{~km}$ wide, with depths of up to $6 \mathrm{~m}$. The radius of curvature reached $1.6 \mathrm{~km}$, the rate of lateral erosion up to $11 \mathrm{~m} /$ year. The inside part of the river bend is a vast (about 5 $\mathrm{km}^{2}$ ) accumulative formation consisting of the remains of accumulated islands that make up the core of accumulative forms, on which the floodplain formations of recent stages of relief formation are leaning. The Levoberezhnaya channel acquires the features of a straight-line channel due to the construction of a new section of bank protection structures. New floodplain islands and channels bars were formed. The main channel is shallower. In the peripheral part of the Delta (area 3), flooding and blurring of previously formed sections of subaerial surfaces continues (more than $50 \mathrm{~km}^{2}$ ). The Kazanova branch and other channels are beginning to form with the interception of the flow from the Lobanovskaya branch The general extension of the flank sections of the Delta is insignificant. Satellite image reflects the morphodynamics of river network of the Delta for the longest stage of low water in recent years. Low water and low regulated level of the receiving reservoir created specific conditions for relief formation. Maximum deformations of the Delta relief continue to be observed on the northern periphery of the Delta. The coastline recedes, and low-lying areas of land are filled with the waters of Lake Baikal, forming liman lakes. With relatively stable and low water content in the Baikal basin, there is flooding of the northern edge of the Delta and the extension of the left and right flanks, which may be due to an endogenic process: the lowering of significant sections of land along inherited faults.

\section{Conclusion}

Periods of low and high water content and their reaction to the fluvial process of relief formation are highlighted. It is noted that the accumulation of sediments that form channel relief forms exceeds the erosion activity of the branches. High-water periods are characterized by the restructuring of the river network with the formation of new branches, the extension of the flank parts of the Delta. During periods of low water content, channel deformations are stabilized, the rate of embedding of river bends is reduced, islands are formed, and accumulative protrusions are formed in the river mouth branches. The considered period of cartographic analysis of the Selenga Delta revealed significant areas disappearing from the aerial part of it, which requires separate detailed studies.

The work was financially supported by the RFBR grant 17-29-05052 ofi m "Exomorpholithogenesis of the mouths of the Baikal tributaries at the present stage of the hydroclimatic cycle: modeling and forecast". 


\section{References}

1. M. M. Ainbund, N. A. Davtyan, A. S. Sudol'skii, V. A. Fialkov. Proc. of the VII allunion Hydrological Congress, 5, 356-365 (1975)

2. N. Afanas'ev. Proc. of the Limn institute SO AN SSSR, Irkutsk, 25(45), 238 (1976)

3. L. V. Zorin. Formation of the Selenga Delta and the formation of the Gulf of Proval. Memoirs of the Faculty of Geomorhology, 182, 193-196 (1956)

4. E. E. Kononov, O. M. Khlystov. Proceedings of the Siberian Department of the Section of ES RANS. Geology, Exploration and Development of Mineral Deposits. 40 (4), 118 129 (2017)

5. V. N. Mikhailov. SSEP, 7(3), 59-66 (2001)

6. V. D. Mats, I. M. Efimova. GT-CRUST, 2(2), 175-193 (2011)

7. V. M. Nikitin, N. V. Abasov, T. V. Berezhnykh, E .N. Osipchuk. Geography and Natural Resources, 5, 29-38 (2016)

8. A. A. Rogozin. The coastal zone of Baikal and Khubsugul: Morphology, dynamics and history of development. Novosibirsk, Nauka (1993) 